\title{
ROLE OF LEPTIN IN EARLY METABOLIC PROGRAMMING
}

\section{Arieh Gertler}

Institute of Biochemistry, Food Science and Nutrition, The Hebrew University of Jerusalem (HUJ), Rehovot, Israel.

\begin{abstract}
Experimental studies in rodents have highlighted the relationship between early postnatal events, undernutrition during pregnancy and/or lactation and the subsequent development of metabolic syndrome, a phenomenon termed developmental programming. However, appearance of metabolic syndrome is dependent not only on prenatal or postnatal predisposition but also on type of nutrition throughout the life cycle. Those experimental findings have been supported by epidemiological data in humans, born to mothers who suffered undernutrition during pregnancy. Leptin is likely involved is such programming and maintaining a critical leptin level during development may allow normal maturation of tissues and pathways involved in metabolic homeostasis, reversing the undesired effects. Leptin disruption during a critical neonatal or prenatal window is sufficient to permanently alter long-term metabolic regulation. Thus, in rodents (in the early postnatal phase), and likely in other species such as primates, and including humans (in the prenatal period), leptin plays a major role in the development of brain circuits which affect future developmental programming of metabolic disease. As postnatal nutritional or therapeutic intervention can ameliorate the consequences of developmental malprogramming, use of leptin as an additive to milk in infant formula which, in contrast to maternal milk, which is devoid of this protein, has been suggested. Alternatively, identification of potential factors elevating leptin levels in maternal milk may also be beneficial. In conclusion, the present data highlight the importance of leptin in the developmental induction of metabolic disease and offer exciting new strategies for therapeutic intervention, by either maternal or neonatal intervention or targeted nutritional manipulation in postnatal life.
\end{abstract}

Adipobiology 2009; 1: 27-34

Keywords: leptin, metabolic programming, obesity, brain-circuit development, developmental plasticity
Received 30 July 2009, accepted 14 August 2009.

Correspondence and reprint request: Dr Arieh Gertler, Institute of Biochemistry, Food Science and Nutrition, The Hebrew University of Jerusalem (HUJ), Rehovot 76100, Israel. Tel./Fax: 97289 489 006, Email: gertler@agri.huji.ac.il

\section{Leptin discovery: hopes and failures}

The discovery of leptin, the obese $(o b)$ gene product which is not expressed as a functional protein in $o b / o b$ mice (1), focused the scientific community's attention on its role as an anorexic hormone involved in the negative regulation of food intake. In both wild-type and mutant mice, leptin treatments were found to dramatically reduce body weight by inhibiting food intake and stimulating the depletion of body fat (2-4). However, hopes of using leptin as a therapeutic agent for obesity in humans faded rapidly as it became evident that leptin deficiency was an extremely rare condition in the general population (5). The main source of leptin is white adipose tissue and systemic leptin levels generally reflect concurrent fat mass. As a consequence, hyperleptinemia is found in most cases of obesity. In this context, leptin resistance has been identified as a central feature of the pathogenesis of obesity (6). Leptin activity in the central nervous system (CNS) is dependent on the transport of leptin across the blood-brain barrier (BBB), which is mediated by a saturable receptormediated transport system located in the brain microvasculature and choroid plexus (7). Impaired leptin 
transport across the $\mathrm{BBB}$ has also been proposed as a possible causal mechanism for the development of leptin resistance and obesity $(7,8)$.

Now, over 15 years after its discovery and with over 16,000 leptin-related publications, leptin is known to participate in a wide range of biological functions that include, in addition to its early envisaged function as an adipostat, glucose metabolism, glucocorticoid synthesis, CD4+ T-lymphocyte proliferation, cytokine secretion, phagocytosis, hypothalamic-pituitary-adrenal axis regulation, reproduction, cardiovascular pathology, apoptosis and angiogenesis (9). In short, it is now well-documented that leptin acts like a cytokine hormone with many pleiotropic effects. Furthermore, in recent years, it has become more and more apparent that many of leptin's effects are acquired not only through its central action, but also through its systemic action at the peripheral level.

\section{Postnatal leptin activity in rodents}

In the last 5 years, a novel function for leptin has been discovered. In initial experiments carried out by the Auckland group $(10,11)$ and as confirmed by others (12), rats were subjected to maternal undernutrition by providing only $30 \%$ of ad-libitum intake to pregnant rat. At weaning, offspring were assigned to either a control diet or a hypercaloric (30\% fat) one. Food intake in offspring from undernourished mothers was significantly elevated at an early postnatal age. It increased further with advancing age and was enhanced by the hypercaloric high-fat diet (HFD), accompanied by elevated systolic blood pressure and markedly increased fasting plasma insulin and leptin concentrations. This study (10) was the first to demonstrate that profound adult hyperphagia may be a consequence of fetal programming, a key contributing factor in adult pathophysiology. As undernutrition is characterized by extremely low leptin levels, we investigated the effects of early postnatal leptin treatment of female rat pups on the metabolic phenotype of the adult female offspring. Recombinant rat leptin $(2.5 \mu \mathrm{g} / \mathrm{g}$.day) was injected subcutaneously (sc) from postnatal days 3 to 13 . This treatment, followed by exposure to a HFD, resulted in a transient slowing of neonatal weight gain, and normalized caloric intake, locomotor activity, body weight, fat mass, and fasting plasma glucose, insulin, and leptin concentrations in adults, in contrast to the saline-treated offspring of undernourished mothers who developed abnormal levels of all of these features on the HFD (13). This indicated that postnatal programming along with a HFD leading to obesity is reversible. The complete normalization of the programmed phenotype by neonatal leptin treatment implies that leptin reversed the prenatal adaptations resulting from fetal undernutrition.

However, it seems that the postnatal leptin effect may differ between female and male rats. In our recent study with male rat pups (14), the long-term effects of neonatal leptin treatment on body composition and metabolism in male offspring were dependent upon prior developmental programming and postnatal nutrition. Neonatal leptin treatment promoted obesity in male offspring of ad-libitum-fed mothers, particularly when they were given a subsequent HFD, whereas in males born to undernourished mothers, it prevented diet-induced obesity, but only if the animals were fed a standard chow diet. No such protective effect was seen when these male rats were fed a HFD. These findings were in contrast to those found with female pups (13). The results observed for male offspring of mothers who were adequately fed during pregnancy were in agreement with those recently reported by others $(15,16)$. However, as in the latter study only male offspring of normal control dams were treated with leptin, the potential interaction between developmental programming and alterations in neonatal leptin levels was not addressed. In addition, gender-specific differences associated with neonatal leptin treatment were not investigated. Our results were also later confirmed by another group (17-19) who administered leptin orally in physiological doses simulating the natural effects of lactation. They demonstrated that neonate rats treated orally with physiological amounts of leptin during the suckling period are more resistant to age-related increases in body weight in adulthood $(17,18)$ and also more resistant to dietary obesity induced by feeding of a HFD (17). Leptin treatment during lactation prevented excess body-weight gain due to HFD feeding, and these animals had a body weight similar to untreated control animals under a normal-fat diet (17).

To verify the role of leptin in postnatal programming, we treated 2-day-old female rat pups with 10 daily sc injections of a rat leptin antagonist (the higher, more effective dose was $7.5 \mathrm{mg} / \mathrm{kg}$ day) which was recently developed in our lab (20). Leptin disruption from day 2 to day 13 led to long-term leptin resistance as evidenced, at 4 months of age, by loss of the treated animals' ability to respond to leptin by reducing food intake and body weight (21). Moreover, the leptin-antagonisttreated animals presented higher susceptibility to diet-induced obesity, as shown by higher body-weight gain when subjected to a HFD, associated with increased adiposity and leptinemia. The susceptibility to obese phenotype was revealed when at the age of 5 months, the rats were transferred from a normocaloric diet to a high-fat, highly palatable diet (Table 1). This observation is reminiscent of that which is usually observed in the case of developmental programming that results from a combination between prenatal undernutrition and postnatal overnutrition. (22). This study clearly demonstrated that in normal rats, independent of adverse fetal programming or genetic de- 
Table 1. Effect of rat leptin antagonist (RLA) treatment of neonatal rats on long-term effects tested after 4 and 9 months (m)

\begin{tabular}{|c|c|c|c|}
\hline Parameter tested & Control $^{1}$ & RLA $^{1}$ & Significance \\
\hline Weight after $3 \mathrm{~m}$ (g/rat) & $250 \pm 6$ & $248 \pm 5$ & NS \\
\hline Leptin after 3 m (ng/ml) & $1.3 \pm 0.2$ & $1.0 \pm 0.1$ & NS \\
\hline$\Delta$ Food intake in response to leptin after $4 \mathrm{~m}(\%)$ & -26.2 & -0.0 & NM \\
\hline$\Delta$ Weight gain in response to leptin after $4 \mathrm{~m}(\%)$ & $-4.3 \pm 0.8$ & -0.0 & $p<0.05$ \\
\hline Weight gain in response to HFD after $9 \mathrm{~m}$ (g/rat) & $32.9 \pm 4.5$ & $49.4 \pm 5.0$ & $p<0.05$ \\
\hline Abdominal fat in response to HFD after $9 \mathrm{~m}$ (g/rat) & $29.5 \pm 4.4$ & $39.0 \pm 4.4$ & NS \\
\hline Adiposity in response to HFD after $9 \mathrm{~m}(\%)$ & $8.1 \pm 0.5$ & $10.1 \pm 0.7$ & $p=0.053$ \\
\hline Serum leptin in response to HFD after $9 \mathrm{~m}(\mathrm{ng} / \mathrm{ml})$ & $4.2 \pm 0.8$ & $14.4 \pm 3.1$ & $p<0.05$ \\
\hline Serum insulin in response to HFD after $9 \mathrm{~m}(\mathrm{ng} / \mathrm{ml})$ & $1.2 \pm 0.3$ & $1.3 \pm 0.3$ & \\
\hline
\end{tabular}

${ }^{1}$ The results are presented as mean $\pm \mathrm{SEM}$

HFD - high-fat diet, NS - not significant, NM - not measurable

ficiency, leptin disruption during a critical neonatal window is sufficient to permanently alter the long-term metabolic regulation. These results indicated that the postnatal leptin surge, occurring normally in neonatal rodents $(23,24)$, is crucial to ensuring adequate metabolic regulation, and that leptin levels may be a limiting factor during the first 2 weeks of life, at least in rodents, for the onset of normal food-intake regulation. Interestingly, at this stage, leptin regulates metabolic rate, brain circuit formation and hypothalamic neuropeptide expression, but not food intake (25-27).

\section{Involvement of leptin in the development of brain circuits in rodents}

The role of the hypothalamus as a main target for leptin action was demonstrated in as early as 1997 in adult animals (28). Later, it was documented that CNS-specific deletion of leptin receptors leads to obesity $(29,30)$. In contrast, transgenic brainspecific restoration of leptin receptors in leptin-receptor-deficient $\left(\right.$ Lepr $\left.^{\mathrm{db}} / \operatorname{Lepr}^{\mathrm{db}}\right)$ mice reduced obesity $(31,32)$. Within the arcuate nucleus (ARH) located in the third ventricle, leptin acts on two distinct populations of neurons: one is activated by leptin and subsequently promotes weight loss and decreased appetite, expresses $\alpha$-melanocyte-stimulating hormone ( $\alpha-\mathrm{MSH}$; derived from the pro-opiomelanocortin (POMC) precursor and cocaine- and amphetamine-regulated transcript (CART); the other promotes weight gain and is inhibited by leptin, and coexpresses neuropeptide Y (NPY) and agouti-related peptide (AgRP) (33). It was documented over 10 years ago that many of the biological effects of leptin are transmitted through projection pathways emanating from these two populations of arcuate neurons to the paraventricular nucleus (PVH) and the lateral hypothalamic area (LHA), as well as to the dorsomedial nucleus (DMH) (33-38). The pioneering study by Bouret and his colleagues $(39,40)$ was the first to demonstrate that leptin acts as a key neurotrophic factor and is cardinal for promoting the maturation of key neural pathways in the hypothalamus, and in particular in the ARH. A series of studies (for the most recent reviews see references 41,42) showed that in mice, leptin is indispensible for the development of the neural circuits responsible for future regulation of food intake in adult animals. It should be noted that those circuits are immature at birth and develop in a time-limited window in the early postnatal phase. Briefly, the innervation of DMH occurs on day 6, that of PVH on days 8-10 and that of LHA on days 10-12. The density of axons from arcuate neurons that innervate other hypothalamic sites involved in the control of energy homeostasis (such as the PVH, $\mathrm{DMH}$, and LHA) is severely reduced in $o b / o b$ mouse neonates and remains diminished throughout life (39). Those findings may explain, at least in part, the development of obesity in adult rodents born to dams made hypoleptinemic by maternal undernutrition during pregnancy (43). An interesting observation regarding development of the hypothalamic leptin response was recently made using the intrauterine growth retardation (IUGR) pig model (44-47). We found that in normal-weight piglets leptin receptor expression is mainly localized in the ARH, whereas in female IUGR piglets, it is $\sim 40 \%$ lower and localized almost equally to the ARH and PVH (48). Such differences in leptinreceptor distribution may hint at lower leptin sensitivity and in sheep, it has been attributed to lower hypothalamic structural development (49). In conclusion, though leptin does not appear 
to regulate food intake or body weight during neonatal life in rodents, its remarkably high plasma levels reported during the postnatal period in both mice, termed "leptin surge" $(23,24)$, and rats $(27,50,51)$ suggests that this metabolically irrelevant surge in fact acts as a developmental signal (24).

\section{Leptin as growth factor}

Several reports have indicated that leptin can stimulate cell proliferation in several peripheral organs, such as the kidney (52), pancreas (53) and stomach (54), as well as in osteoblasts (55), breast cancer cells (56), colonic epithelium (57) and gastric mucosa cells (58). In most of these organs and cells, except adipose tissue, leptin also exhibits potent antiapoptotic activity (reviewed in 59). However, such growth-promoting effects may be dependent upon developmental stage, as they are detected mainly when organ maturation is incomplete (such as in IUGR) and they are not always seen in normally developing animals. In recent work, we developed a novel model for studying leptin action using low-birth-weight female piglets taken from the lower third of the litter and weighing between 1.01 and $1.35 \mathrm{~kg}$ (48). These IUGR piglets showed a general developmental delay, as evidenced by their reduced body weight and size, as well as diminished growth of almost all organs. Intramuscular leptin administration $(0.5 \mathrm{mg} / \mathrm{kg}$ day) through postnatal days 2 to 10 induced, within a few days, a rapid increase in the weight and size of IUGR animals and an increase their lean mass to values of control piglets from the upper third of the litter. Analysis of individual organ weights showed an apparent improvement in the growth of organs involved in metabolic regulation, such as the pancreas, liver, and to a minor extent, kidneys. In addition, leptin was able to increase lung weight, which may reflect better maturation of this organ. It should be noted that in normal-body-weight piglets, leptin injections were not effective at increasing organ weight, though overall body weight gain did improve. Leptin treatment also normalized the structural organization of the adipose tissue resulting in a more differentiated stage, and in a $25 \%$ lower density of white adipocytes, a lower number of adipocytes, and an apparently equal number of adipocytes in leptin-treated IUGR and control animals. Such changes may affect the susceptibility of IUGR piglets to the development of obesity. In addition, leptin increased brown adipose tissue content, probably leading to improved thermogenic capacity as shown in fetal and newborn sheep $(60,61)$, a factor which is important for neonatal survival.

\section{The role of leptin in prenatal and postnatal human development}

Experimental findings in rodents, sheep and pigs raise some fundamental questions: to what extent are these findings relevant to humans and does leptin play any important role? Barker $(62,63)$ focused on the relationship between birth weight and adult disease and suggested a connection between low birth weight and an increased propensity for hypertension, obesity and insulin resistance later in life. Those observations were supported by findings related to the Dutch Famine in the winter of 1944-1945, when reduced maternal caloric intake in late gestation was associated with a higher prevalence of adult obesity occurring in individuals who were of low birth weight at that time. Low birth weight and rapid postnatal weight gain, or catch-up growth, are independent risk factors for the development of obesity and diabetes in adulthood $(64,65)$. Interestingly, individuals with high birth weights (e.g. offspring of mothers with gestational diabetes) exhibit a similar phenotype $(64,66,67)$, indicating that developmental programming may involve a U-shaped relationship between disease prevalence and birth weight. As undernutrition is accompanied by hypoleptinemia, leptin involvement was suggested. Indeed, IUGR children have been shown to have low cord-blood and plasma leptin levels (68), which are associated with rapid postnatal weight gain and a predisposition for developing metabolic syndrome in adulthood (69). Conversely, maternal obesity and/or gestational diabetes results in elevated cord-blood leptin levels and in children being born at increased risk for developing metabolic syndrome (70). Thus a period of relative hypo- or hyperleptinemia may induce maladaptive metabolic changes which contribute to the developmental programming of adult disease $(71,72)$. It seems, therefore, that both the timing and the magnitude of gestational food restriction are critical in determining the obese phenotype. For example, in the Dutch Famine study, the rate of obesity was higher in men exposed in the first half of gestation and lower in men exposed in the last trimester of gestation to maternal undernourishment than in non-exposed men (66). The precise mechanisms responsible for these phenomena may vary with the timing of exposure and are not clear, but there is increasing evidence of intergenerational effects. It has been shown that babies born at both ends of the birth-weight spectrum may develop a phenotype of excess weight gain. In girls, such obesity predisposes them to diabetes in pregnancy, which accelerates a cycle of early diabetes in subsequent generations (73).

The similarity of late phenotypic development in rodents and primates, including humans, occurs despite the fact that hypothalamic neurogenesis in primates occurs in the first quarter of gestation $(74,75)$. The information on human fetal brain architecture, though limited, suggests that early hypothalamic neurogenesis occurs mainly in the ninth and tenth weeks of gestation 
(76-80). Furthermore, while the hypothalamic feeding circuits in rodents develop postnatally during the first 2 weeks of life, these circuits appear to develop in utero in primates, including humans. In Japanese macaques, NPY/AgRP fibers are already innervating the PVH in the late second trimester of gestation (81) and in human fetuses, NPY immunoreactive fibers are detected in the ARH and PVH at as early as 21 weeks of gestation (82), showing that development of neural projection in humans occurs later than neurogenesis.

Many epidemiological studies comparing forms of nutrition during lactation are presenting more and more evidence that breastfeeding, but not infant formula, confers protection against obesity later in life. A meta summary of studies on duration of breastfeeding and risk of becoming overweight (83) strongly supports the notion that there is a dose-dependent association between longer duration of breastfeeding and decreased risk of becoming overweight. Though the exact reason for these differences has not yet been elucidated, there is some evidence of leptin involvement. Leptin is present in milk synthesized in the mammary gland (84), and in nursing rats, the leptin in milk has been shown to be transferred from the mother's circulation (85). Leptin concentrations in human milk vary significantly, but there is a positive correlation between leptin concentration in milk and maternal plasma leptin levels and adiposity $(86,87)$, suggesting that the amount of leptin supplied to infants through breast milk depends on the mother's adiposity. Furthermore breast-fed infants have higher plasma leptin values than formula-fed infants (88).

As concluded by Palou and Pico (19), these findings have opened a new area of research on both the use of leptin in the design of more appropriate infant formulas and the identification of potential factors influencing leptin levels in maternal milk, which are aspects of great relevance due to the increasing prevalence of obesity and its associated health complications.

\section{Conclusions}

Blockage of leptin actions during a critical period of early life in rodents may have long-term consequences by altering the capacity to respond to leptin in terms of food intake and glucose metabolism during adulthood. This is likely associated with the impaired leptin-dependent neurogenesis and maturation of brain circuits. A similar situation probably exists in other animals as well, such as pigs, sheep, primates and in particular humans, though the timing of the "narrow windows of opportunity" may be temporally different. Milk leptin is also a credible candidate to explain, at least in part, the protective effect of breast feeding on the prevalence of adult obesity and development of metabolic syndrome.

\section{References}

1. Zhang Y, Proenca R, Maffei M, Barone M, Leopold L, Friedman JM. Positional cloning of the mouse obese gene and its human homologue. Nature 1994; 372: 425-432.

2. Halaas JL, Gajiwala KS, Maffei M, et al. Weight-reducing effects of the plasma protein encoded by the obese gene. Science 1995; 269: 543-546.

3. Maffei M, Halaas J, Ravussin E, Pratley RE, Lee GH, Zhang $\mathrm{Y}$, et al. Leptin levels in human and rodent: measurement of plasma leptin and ob RNA in obese and weight-reduced subjects. Nat Med 1995; 1: 1155-1161.

4. Pelleymounter MA, Cullen MJ, Baker MB, Hecht R, Winters D, Boone T, et al. Effects of the obese gene product on body weight regulation in ob/ob mice. Science 1995; 269: 540-543.

5. Farooqi IS, Jebb SA, Langmack G, Lawrence E, Cheetham $\mathrm{CH}$, Prentice AM, et al. Effects of recombinant leptin therapy in a child with congenital leptin deficiency. $N$ Engl J Med 1999; 341: 879-884.

6. Zhang Y, Scarpace PJ. The role of leptin in leptin resistance and obesity. Physiol Behav 2006; 88: 249-256.

7. Banks WA, Kastin AJ, Huang W, Jaspan JB, Maness LM. Leptin enters the brain by a saturable system independent of insulin. Peptides 1996; 17: 305-311.

8. Banks WA. Blood-brain barrier and energy balance. Obesity (Silver Spring) 2006; 14 (Suppl 5): 234S-237S.

9. Gertler A, editor. Leptin and Leptin Antagonists. Landes Biosciences, 2009.

10. Vickers MH, Breier BH, Cutfield WS, Hofman PL, Gluckman PD. Fetal origins of hyperphagia, obesity, and hypertension and postnatal amplification by hypercaloric nutrition. Am J Physiol Endocrinol Metab 2000; 279: E83-E87.

11. Vickers MH, Breier BH, McCarthy D, Gluckman PD. Sedentary behavior during postnatal life is determined by the prenatal environment and exacerbated by postnatal hypercaloric nutrition. Am J Physiol Regul Integr Comp Physiol 2003; 285: R271-R273.

12. Symonds ME, Budge H, Stephenson T, Gardner DS. Experimental evidence for long-term programming effects of early diet. Adv Exp Med Biol 2005; 569: 24-32.

13. Vickers MH, Gluckman PD, Coveny AH, Hofman PL, Cutfield WS, Gertler A, et al. Neonatal leptin treatment reverses developmental programming. Endocrinology 2005; 146: 4211-4216.

14. Vickers MH, Gluckman PD, Coveny AH, Hofman PL, Cutfield WS, Gertler A, et al. The effect of neonatal leptin treatment on postnatal weight gain in male rats is dependent on 
maternal nutritional status during pregnancy. Endocrinology 2008; 149: 1906-1913.

15. Yura S, Itoh $H$, Sagawa $N$, Yamamoto $H$, Masuzaki $H$, Nakao K, et al. Role of premature leptin surge in obesity resulting from intrauterine undernutrition. Cell Metab 2005; 1: 371-378.

16. Yura $S$, Itoh $H$, Sagawa $N$, Yamamoto $H$, Masuzaki $H$, Nakao K, Kawamura M, et al. Neonatal exposure to leptin augments diet-induced obesity in leptin-deficient $o b / o b$ mice. Obesity 2008; 16: 1289-1295.

17. Pico C, Oliver P, Sanchez J, Miralles O, Caimari A, Priego $\mathrm{T}$, et al. The intake of physiological doses of leptin during lactation in rats prevents obesity in later life. Int J Obesity (London) 2008; 31: 1199-1209.

18. Sanchez J, Priego T, Palou, M., Tobaruela A, Palou A, Pico C. Oral supplementation with physiological doses of leptin during lactation in rats improves insulin sensitivity and affects food preferences later in life. Endocrinology 2008; 149: 733-740.

19. Palou A, Pico C. Leptin intake during lactation prevents obesity and affects food intake and food preferences in later life. Appetite 2009; 52: 249-252.

20. Salomon G, Niv-Spector L, Gussakovsky EE, Gertler A. Large-scale preparation of biologically active mouse and rat leptins and their L39A/D40A/F41A muteins which act as potent antagonists. Protein Expr Purif 2006; 47: 128136.

21. Attig L, Solomon G, Ferezou J, Abdennebi-Najar L, Taouis M, Gertler A, et al. Early postnatal leptin blockage leads to a long-term leptin resistance and susceptibility to diet-induced obesity in rats. Internat J Obesity 2008; 32: 1-8.

22. Godfrey KM, Lillycrop KA, Burdge GC, Gluckman PD, Hanson MA. Epigenetic mechanisms and the mismatch concept of the developmental origins of health and disease. Pediatr Res 2007; 61: 5R-10R.

23. Devaskar SU, Ollesch C, Rajakumar RA, Rajakumar PA. Developmental changes in ob gene expression and circulating leptin peptide concentrations. Biochem Biophys Res Commun 1997; 238: 44-47.

24. Ahima RS, Prabakaran D, Flier JS. Postnatal leptin surge and regulation of circadian rhythm of leptin by feeding. Implications for energy homeostasis and neuroendocrine function. J Clin Invest 1998; 101: 1020-1027.

25. Mistry AM, Swick A, Romsos DR. Leptin alters metabolic rates before acquisition of its anorectic effect in developing neonatal mice. Am J Physiol 1999; 277: R742-R747.

26. Ahima RS, Hileman SM. Postnatal regulation of hypothalamic neuropeptide expression by leptin: implications for energy balance and body weight regulation. Regul Pept 2000; 92: 1-7.

27. Proulx K, Richard D, Walker CD. Leptin regulates appetiterelated neuropeptides in the hypothalamus of developing rats without affecting food intake. Endocrinology 2002; 143: 4683-4692.

28. Halaas JL, Boozer C, Blair-West J, Fidahusein N, Denton DA, Friedman JM. Physiological response to long-term peripheral and central leptin infusion in lean and obese mice. Proc Natl Acad Sci USA 1997; 94: 8878-8883.

29. Cohen P, Zhao C, Cai X, Montez JM, Rohani SC, Feinstein $\mathrm{P}$, et al. Selective deletion of leptin receptor in neurons leads to obesity. J Clin Invest 2001; 108: 1113-1121.

30. McMinn JE, Liu S-M, Liu H, Dragatsis I, Dietrich P, Ludwig $\mathrm{T}$, et al. Neuronal deletion of LepR elicits diabesity in mice without affecting cold tolerance or fertility. Am J Physiol Endocrinol Metab 2005; 289: E403-E411.

31. Kowalski TJ, Liu S-M, Leibel RL, Chua SC Jr. Transgenic complementation of leptin-receptor deficiency. I. Rescue of the obesity/diabetes phenotype of LEPR-null mice expressing a LEPR-B transgene. Diabetes 2001; 50: 425-435.

32. de Luca C, Kowalski TJ, Zhang Y, Elmquist JK, Lee C, Kilimann MW, et al. Complete rescue of obesity, diabetes, and infertility in $\mathrm{db} / \mathrm{db}$ mice by neuron-specific LEPR-B transgenes. J Clin Invest 2005; 115: 3484-3493.

33. Elmquist JK, Coppari R, Balthasar N, Ichinose M, Lowell $\mathrm{BB}$. Identifying hypothalamic pathways controlling food intake, body weight, and glucose homeostasis. J Comp Neurol 2005; 493: 63-71.

34. Sawchenko PE. Toward a new neurobiology of energy balance, appetite, and obesity: the anatomists weigh in. J Comp Neurol 1998; 402: 435-441.

35. Cone RD, Cowley MA, Butler AA, Fan W, Marks DL, Low $\mathrm{MJ}$. The arcuate nucleus as a conduit for diverse signals relevant to energy homeostasis. Int J Obes Relat Metab Disord 2001; 25: S63-S67.

36. Elmquist JK, Ahima RS, Elias CF, Flier JS, Saper CB. Leptin activates distinct projections from the dorsomedial and ventromedial hypothalamic nuclei. Proc Natl Acad Sci USA 1998; 95: 741-746.

37. Elias CF, Aschkenasi C, Lee C, Kelly J, Ahima RS, Bjorbæk $\mathrm{C}$, et al. Leptin differentially regulates NPY and POMC neurons projecting to the lateral hypothalamic area. Neuron 1999; 23: 775-786.

38. Thompson RH, Swanson LW. Organization of inputs to the dorsomedial nucleus of the hypothalamus: a reexamination with Fluorogold and PHAL in the rat. Brain Res Rev 1998; 27: 89-118. 
39. Bouret SG, Draper SJ, Simerly RB. Trophic action of leptin on hypothalamic neurons that regulate feeding. Science 2004; 304: 108-110.

40. Bouret SG, Simerly RB. Minireview: leptin and development of hypothalamic feeding circuits. Endocrinology 2004; 145: 2621-2626.

41. Bouret SG, Simerly RB. Development of leptin-sensitive circuits. J Neuroendocrinol 2007; 19: 575-582.

42. Bouret SG. Early life origins of obesity: role of hypothalamic programming. J Pediatric Gastroenterol Nutr 2009; 48: S31-S38.

43. Ferezou-Viala J, Roy AF, Serougne C, Gripois D, Parquet $\mathrm{M}$, Bailleux V, et al. Long-term consequences of maternal high-fat feeding on hypothalamic leptin sensitivity and diet-induced obesity in the offspring. Am J Physiol Regul Integr Comp Physiol 2007; 293: R1056-R1062.

44. Poore KR, Forhead AJ, Gardner DS, Giussani DA, Fowden AL. The effects of birth weight on basal cardiovascular function in pigs at 3 months of age. J Physiol 2002; 539: 969-978.

45. Poore KR, Fowden AL. The effect of birth weight on glucose tolerance in pigs at 3 and 12 months of age. Diabetologia 2002; 45: 1247-1254.

46. Poore KR, Fowden AL. The effect of birth weight on hypothalamopituitary-adrenal axis function in juvenile and adult pigs. J Physiol 2003; 547: 107-116.

47. Poore KR, Fowden AL. The effects of birth weight and postnatal growth patterns on fat depth and plasma leptin concentrations in juvenile and adult pigs. J Physiol 2004; 558: 295-304.

48. Attig L, Djiane J, Gertler A, Rampin A, Larcher T, Boukthir $\mathrm{S}$, et al. Study of hypothalamic leptin receptor expression in low-birth-weight piglets and effects of leptin supplementation on neonatal growth and development. Am J Physiol Endocrinol Metab 2008; 295: 1117-1125.

49. Muhlhausler BS, McMillen IC, Rouzaud G, Findlay PA, Marrocco EM, Rhind SM, et al. Appetite regulatory neuropeptides are expressed in the sheep hypothalamus before birth. J Neuroendocrinol 2004; 16: 502-507.

50. Smith JT, Waddell BJ. Developmental changes in plasma leptin and hypothalamic leptin receptor expression in the rat: peripubertal changes and the emergence of sex differences. J Endocrinol 2003; 176: 313-319.

51. Rayner DV, Dalgliesh GD, Duncan JS, Hardie LJ, Hoggard N, Trayhurn P. Postnatal development of the ob gene system: elevated leptin levels in suckling fa/fa rats. Am J Physiol Regul Integr Comp Physiol 1997; 273: R446-R450.

52. Wolf G, Hamann A, Han DC, Helmchen U, Thaiss F, Ziyadeh FN, Stahl RA. Leptin stimulates proliferation and
TGF-beta expression in renal glomerular endothelial cells: potential role in glomerulosclerosis. Kidney Int 1999; 56: 860-872.

53. Tanabe K, Okuya S, Tanizawa Y, Matsutani A, Oka Y. Leptin induces proliferation of pancreatic beta cell line MIN6 through activation of mitogen-activated protein kinase. Biochem Biophys Res Commun 1997; 241: 765-768.

54. Islam MS, Sjöholm A, Emilsson V. Fetal pancreatic islets express functional leptin receptors and leptin stimulates proliferation of fetal islet cells. Int J Obes Relat Metab Disord 2000; 24: 1246-1253.

55. Gordeladze JO, Drevon CA, Syversen U, Reseland JE. Leptin stimulates human osteoblastic cell proliferation, de novo collagen synthesis and mineralization: impact on differentiation markers, apoptosis and osteoclastic signaling. $J$ Cell Biochem 2002; 85: 825-836.

56. Dieudonne MN, Machinal-Quelin F, Serazin-Leroy V, Leneveu MC, Pecquery R, Giudicelli Y. Leptin mediates a proliferative response in human MCF7 breast cancer cells. Biochem Biophys Res Commun 2002; 293: 622-628.

57. Hardwick JC, Van Den Brink GR, Offerhaus GJ, Offerhaus GJ, Van Deventer SJ, Peppelenbosch MP. Leptin is a growth factor for colonic epithelial cells. Gastroenterology 2001; 121: 79-90.

58. Schneider R, Bornstein SR, Chrousos GP, Boxberger S, Ehninger G, Breidert M. Leptin mediates a proliferative response in human gastric mucosa cells with functional receptor. Horm Metab Res 2001; 33: 1-6.

59. Rayalam S, Della-Ferra MA, Ambati S, Baile CA. Is leptin a pro- or anti-apoptoti agent? In: Gertler A, editor. Leptin and Leptin Antagonists. Landes Biosciences, 2009; 43-53.

60. Mostyn A, Bispham J, Pearce S, Evens Y, Raver N, Keisler $\mathrm{DH}$, et al. Differential effects of leptin on thermoregulation and uncoupling protein abundance in the neonatal lamb. FASEB J 2002; 16: 1438-1440.

61. Yuen BS, Owens PC, Muhlhausler BS, Roberts CT, Symonds $\mathrm{ME}$, Keisler $\mathrm{DH}$, et al. Leptin alters the structural and functional characteristics of adipose tissue before birth. FASEB J 2003; 17: 1102-1104.

62. Barker DJ. The origins of the developmental origins theory. J Intern Med 2007; 261: 412-417.

63. Barker DJ. Obesity and early life. Obes Rev 2007; Suppl 1: 45-49.

64. Fernandez-Twinn DS, Ozanne SE. Mechanisms by which poor early growth programs type-2 diabetes, obesity and the metabolic syndrome. Physiol Behav 2006; 88: 234-243.

65. Jimenez-Chillaron JC, Hernandez-Valencia M, Lightner A, Faucette RR, Reamer C, Przybyla R, et al. Reductions in 
caloric intake and early postnatal growth prevent glucose intolerance and obesity associated with low birthweight. Diabetologia 2006; 49: 1974-1984.

66. Ravelli GP, Stein ZA, Susser MW. Obesity in young men after famine exposure in utero and early infancy. N Engl J Med 1976; 295: 349-353.

67. Ravelli AC, van Der Meulen JH, Osmond C, Barker DJ, Bleker OP. Obesity at the age of $50 \mathrm{y}$ in men and women exposed to famine prenatally. Am J Clin Nutr 1999; 70: 811816.

68. Hauguel-de Mouzon S, Lepercq J, Catalano P. The known and unknown of leptin in pregnancy. Am J Obstet Gynecol 2006; 194: 1537-1545.

69. Fonseca VM, Sichieri R, Moreira ME, Moura AS. Early postnatal growth in preterm infants and cord blood leptin. J Perinatol 2004; 24: 751-756.

70. King JC. Maternal obesity, metabolism, and pregnancy outcomes. Annu Rev Nutr 2006; 26: 271-291.

71. Vickers $\mathrm{MH}, \mathrm{Krechowec} \mathrm{SO}, \mathrm{Breier} \mathrm{BH}$. Is later obesity programmed in utero? Curr Drug Target 2007; 8: 923-934.

72. Vickers MH. Developmental programming of adult obesity: the role of leptin. Curr Opin Endocrinol Diabetes Obesity 2007; 14: 17-22.

73. Levin BE. Metabolic imprinting: critical impact of the perinatal environment on the regulation of energy homeostasis. Philos Trans R Soc Lond B Biol Sci 2006; 361: 1107-1121.

74. Keyser A. Development of the Hypothalamus in Mammals. Marcel Dekker Inc, 1979.

75. van Eerdenburg FJ, Rakic P. Early neurogenesis in the anterior hypothalamus of the rhesus monkey. Brain Res Dev Brain Res 1994; 79: 290-296.

76. Bugnon C, Fellmann D, Bresson JL, Clavequin MC. Immunocytochemical study of the ontogenesis of the CRHcontaining neuroglandular system in the human hypothalamus. CR Acad Sci 1982; 294: 491-496.

77. Burford GD, Robinson IC. Oxytocin, vasopressin and neurophysins in the hypothalamo-neurohypophysial system of the human fetus. J Endocrinol 1982; 95: 403-408.
78. Ackland J, Ratter S, Bourne GL, Rees LH. Characterization of immunoreactive somatostatin in human fetal hypothalamic tissue. Regul Pept 1983; 5: 95-101.

79. Mai JK, Lensing-Hohn S, Ende AA, Mai JK, Lensing-Hohn S. Developmental organization of neurophysin neurons in the human brain. J Comp Neurol 1997; 385: 477-489.

80. Koutcherov Y, Mai JK, Ashwell KW, Paxinos G. Organization of human hypothalamus in fetal development. J Comp Neurol 2002; 446: 301-324.

81. Grayson BE, Allen SE, Billes SK, Williams SM, Smith MS, Grove KL. Prenatal development of hypothalamic neuropeptide systems in the nonhuman primate. Neuroscience 2006; 143: 975-986.

82. Koutcherov Y. Organization of human hypothalamus in fetal development. J Comp Neurol 2002; 446: 301-324.

83. Harder T, Bergmann R, Kallischnigg G, Plagemann A. Duration of breastfeeding and risk of overweight: a meta-analysis. Am J Epidemiol 2005; 162: 397-403.

84. Smith-Kirwin SM, O'Connor DM, De Johnston J, Lancey ED, Hassink SG, Funanage VL. Leptin expression in human mammary epithelial cells and breast milk. J Clin Endocrinol Metab 1998; 83: 1810-1813.

85. Casabiell X, Pineiro V, Tome MA, Peino R, Dieguez C, Casanueva FF. Presence of leptin in colostrum and/or breast milk from lactating mothers: a potential role in the regulation of neonatal food intake. J Clin Endocrinol Metab 1997; 82: 4270-4273.

86. Houseknecht KL, McGuire MK, Portocarrero CP, McGuire $\mathrm{MA}$, Beerman K. Leptin is present in human milk and is related to maternal plasma leptin concentration and adiposity. Biochem Biophys Res Commun 1997; 240: 742-747.

87. Miralles O, Sanchez J, Palou A, Pico C. A physiological role of breast milk leptin in body weight control in developing infants. Obesity (Silver Spring) 2006; 14: 1371-1377.

88. Savino F, Nanni GE, Maccario S, Costamagna M, Oggero $\mathrm{R}$, Silvestro L. Breast-fed infants have higher leptin values than formula-fed infants in the first four months of life. $J$ Pediatric Endocrinol Metab 2004; 17: 1527-1532. 